\title{
Social Media and the Impact on Alcohol Consumption: A Study among Academics from a Public University in a Western Amazon City, Porto Velho, Brazil
}

\author{
Rosely Valéria Rodrigues', Marina Gomes Martellet ${ }^{2}$, Giovanna Lorena Nery Tavernard ${ }^{2}$, \\ Sérgio Valério Escobar Filho ${ }^{3}$ \\ ${ }^{1}$ Department of Medicine, Federal University of Rondônia, Porto Velho, Brazil \\ ${ }^{2}$ Academic Nursing, Federal University of Rondônia, Porto Velho, Brazil \\ ${ }^{3}$ Academic Medicine, Federal University of Rondônia, Porto Velho, Brazil \\ Email: valrodrigues@unir.br, marina_martellet@hotmail.com, giovannatavernard1@gmail.com, sergio-escobar@live.com
}

How to cite this paper: Rodrigues, R.V., Martellet, M.G., Tavernard, G.L.N. and Filho, S.V.E. (2019) Social Media and the Impact on Alcohol Consumption: A Study among Academics from a Public University in a Western Amazon City, Porto Velho, Brazil. Social Networking, 8, 113-121. https://doi.org/10.4236/sn.2019.83008

Received: January 30, 2019

Accepted: May 14, 2019

Published: May 17, 2019

Copyright $\odot 2019$ by author(s) and Scientific Research Publishing Inc. This work is licensed under the Creative Commons Attribution International License (CC BY 4.0).

http://creativecommons.org/licenses/by/4.0/

\begin{abstract}
This is a descriptive study of quantitative approach, developed at the Federal University of Rondônia located in the Western Amazon. With the aim of analyzing the frequency of visualization of alcoholic content in the Facebook, Instagram and Snapchat, patterns of consumption, reasons that lead them to drink, most used social network and to correlate how often the users are exposed to alcoholic publications, determining if there was an important link between individual drinking practice during the beginning period and six months later. The information was obtained through the application of questionnaires for incoming students of the freshmen semester, in two moments: a period from August to December 2016/2, and, asking the same students again, from March to June 2017/1. 52.8\% were males in 2016/2 and 57, 9\% of females in 2017/1 with age ranging between 18 and 20 years in both periods. Facebook has proven to be the most used platform among college students. In 2016/2, 63.9\% reported seeing alcohol content at Facebook and consuming that substance, comparing to Instagram with $70.4 \%$, and to Snapchat with $74.1 \%$. In 2017/2, academics reporting viewing alcoholic content on Facebook and consuming those alcoholic beverages accounted for $65.8 \%$, compared to Instagram, $74.1 \%$ and Snapchat $74.4 \%$. "Celebrating a special occasion with friends" is the most cited reason of why claim to consume alcohol. Therelation between exposure to the alcohol content of the virtual media and the network of friends was found imperceptible to the majority of the students, as they mostly do not consider themselves exposed. Many university students start the graduation already consuming alcoholic substances, which explains
\end{abstract}


why there is no significant change in alcohol consumption between the observed moments, although it was found a relationship between the visualization of alcohol content in social networks and consumption, with greater impact on Snapchat.

\section{Keywords}

Social Network, Alcohol, College Students

\section{Introduction}

Over the years, social networks are gaining ground and gradually becoming a major leisure habits. Users access networks for different purposes, such as playing games, talking to friends, posting photos, and other entertainment activities [1]. This way, just like people progressively use social networks, they publish more and more personal information online [2].

Brazil is among the five countries with the largest number of users on the Internet. Teenagers and young adults are the most connected to these social platforms, like Facebook, Instagram and Snapchat are related to a freedom of expression, posting content in real time, showing moments, binging a greater exposure to the daily life moments, which also applies to alcohol consumption [3].

According to the World Health Organization [4], alcohol is the most widely used drug in the world and it is estimated that around two billion people use it, at any degree.

Studies indicate that alcohol consumption is occurring earlier and use of alcoholic substances is related to the health problems among young people. Among university students, alcoholism is very prevalent, as it presents an opportunity where we can find an association between age group and a new social character [5].

In these circumstances, to analyze the characteristics of the life of students and to correlate that with the use of alcoholic beverages leads to a better understand and, when necessary, a chance to intervene in the students' health, guiding the prevention of abusive consumption of alcohol [6].

\section{Methodology}

\subsection{Study Design}

This is a descriptive, cross-sectional and quantitative research. This study was based on previous research on the alcohol intake among university students regarding the perception of outcomes of the increase in consumption as a function of exposure to social networks, in order to observe, record and analyze the characteristics of the university population of the only Public University of Porto Velho/RO Brazil.

The cross-sectional study data allows the sample, in this case, the students of 
the university, to be used to observe the behavior of alcohol consumption and to analyze statistically at a certain time and place.

\subsection{Location of the Study}

Study conducted in Porto Velho, a capital in the Western Amazon, located at the state of Rondônia, north of Brazil, developed at State University of Rondônia (UNIR), Campus Porto Velho/RO.

\subsection{Study Population}

The studied population consists of students who entered the university in the second semester of 2016 school year. Eleven courses were offered: Visual Arts, Biological Sciences, Accounting, Law, Nurse, Civil Engineering, Electrical Engineering, Philosophy, Libras, Medicine and Chemistry.

\subsection{Data Collection Procedures}

The information ware obtained based on the application of questionnaires to freshmen students in two moments: a period from August to December 2016, which characterized 2016/2 semester, and a second period, from March to June of 2017 as $2017 / 1$ semester.

The application of the questionnaires was took in person, taking place in the shifts of the respective courses at the Porto Velho campus that were part of the research, being executed by the scholars proceeding for the study that were present there all time of the interview.

The printed instrument had questions about the following social networks: Facebook, Instagram and Snapchat.

The students were asked about what frequency they usually see advertisements, texts or images with alcohol-related content in their social networks, both individuals who use to drink alcohol or not.

The reasons for drinking are many, ranging from being sociable to forgetting problems, using the Drinking Motives Questionnaire, Revised (DMQ-R), which consists of scaling with reasons why people consume drinks [7], students reported the main reasons they ingest alcohol content.

On a scale of 0 (I do not feel exposed) to 10 (I feel totally exposed), the students marked how much they feel exposed to alcoholic publications. Also, on a scale of 0 (no one consume) to 4 (all friends consume) marked referring to close friends who drink.

\subsection{Analysis of Data}

The data resulting from the applied questionnaires were launched on a virtual platform, tabulated and analyzed statistically using the Software Statistical Package for the Social Sciences (SPSS) version 20.0.

\subsection{Ethical Considerations}

In compliance with the recommendations of resolution 466/12 of the Brazilian 
National Health Council, that considers the participation of individuals in research (Brazil, 2012), the study was submitted to the Research Ethics Committee (CEP) of the State University of Rondônia and approved, with opinion of $\mathrm{n}^{\circ}$. $1,246.624$.

\section{Results}

A total of 319 academics were interviewed in both moments, in 2016/2 the male public had a higher prevalence with $52.8 \%$ and in $2017 / 1$ the female sex was $57.9 \%$, the predominant age group was found between 18 and 20 years in the two moments, according to Table 1.

During the first round of the research, in 2016/2, Facebook was shown to be the most used social platform among the college students, with $96.10 \%$ of incidence, followed by Instagram with $70.99 \%$ and Snapchat with $51.51 \%$. In the second application, Facebook remained the most used network with $90.9 \%$, followed by Instagram with $71.59 \%$ and Snapchat $36.36 \%$.

Table 2 shows the relationship between visualization of alcoholic content in the networks and consumption of alcohol, among the academics who answered the interviews during the second semester of 2016, 63.9\% reported both viewing alcoholic content on the social network Facebook and consuming the substance, besides that, only $23.1 \%$ of those who consume said they did not see any alcohol content present on the social network. As result, the risk (RO) of an academic consuming alcoholic beverages is $5.90 \%$ (IC95\% $=2.26$ to 15.34 ) higher among those who viewed alcoholic content on Facebook, comparing to those who did not visualize.

Taking the usage Instagram social network, the percentage of students viewing and consumption of alcoholic beverages was higher, being $70.4 \%$, and in adding to that, $41.6 \%$ report consuming alcoholic beverages although without seen any alcohol content at the network. Thus, the risk of an academic consuming

Table 1. Characterization of the students participating in the research, at both moments, of the State University of Rondônia, Porto Velho, Brazil.

\begin{tabular}{ccc}
\hline Variable & \multicolumn{2}{c}{$\mathbf{f ( \% ) ^ { * }}$} \\
\cline { 2 - 3 } Sex & $2016 / 2$ & $2017 / 1$ \\
Female & 47.2 & 57.9 \\
Male & 52.8 & 42.1 \\
Age & & \\
$<18$ & 0.8 & - \\
$18-20$ & 58.1 & 47.7 \\
$21-23$ & 13.5 & 21.6 \\
$24-30$ & 17.3 & 15.9 \\
$>30$ & 10.3 & 14.8 \\
\hline
\end{tabular}

${ }^{*}$ Relative Frequency. 
Table 2. Relationship of the frequency of visualization of alcohol content among those participants, consuming alcoholic beverage or not, in 2016/2, from the Federal University of Rondônia Foundation, Porto Velho, Brazil.

\begin{tabular}{cccc}
\hline Visualization & \multicolumn{2}{c}{$\mathbf{f ( \% ) ^ { * }}$} & RO $\left(\mathrm{CI}^{* *}{ }_{95 \%}\right)$ \\
\cline { 2 - 3 } Consume & Sim & Não & \\
Facebook & & & $5.90(2.26$ a 15.34$)$ \\
yes & 63.9 & 36.1 & \\
no & 23.1 & 76.9 & $3.34(1.92$ a 5.82$)$ \\
Instagram & & & \\
yes & 70.4 & 29.6 & \\
no & 41.6 & 58.4 & $3.30(1.89$ a 5.77$)$ \\
Snapchat & & & \\
yes & 74.1 & 25.9 & \\
no & 53.7 & 46.3 & \\
\hline
\end{tabular}

${ }^{\star}$ Relative Frequency, ${ }^{* *}$ Confidence Index.

alcoholic beverages is $3.34 \%(\mathrm{CI} 95 \%=1.92$ to 5.82$)$ among the academics who visualize alcohol content over this domain.

Among the academics using the Snapchat social network, it was seen the greatest potential of users who both view and consume alcoholic beverages, with $74.1 \%$, more than that, $53.7 \%$ of the academics reporting consuming alcoholic beverages and not perceiving it on the social network. As a result, it was demonstrated that the risk of the students who entered in 2016/2 to consume alcoholic beverages was $3.30 \%$ ( $95 \% \mathrm{CI}=1.89$ to 5.77$)$.

In the second part of the application of the questionnaires, during the year 2017/01, as described in Table 3, the students who stated both viewing alcoholic content on Facebook and consuming alcoholic drinks accounted for $65.8 \%$, also, those who consume drinks but do not see any content of this nature online, totaled 53,3\%. This way, the risk of an academic drinking alcoholic beverages is $3.34 \%$ ( $95 \% \mathrm{CI}=1.92$ to 5.82 ) higher among those who view alcoholic content on Facebook, in relation to the others.

As for Instagram, $74.1 \%$ of the academics said that they both viewed publications related to alcoholic content and drank alcoholic beverages, by the other hand $43.3 \%$ of those who reported consuming alcoholic beverages stated that they did not view content. Thus, the risk of an academic consuming alcoholic beverages is $3.30 \%$ (IC95\% $=1.89$ to 5.7 ) among those who visualize content of an alcoholic nature in this network than when we compare to other academics.

The academics who reported both viewing posts of alcoholic content in the Snapchat social network and consuming alcoholic beverages made up a total of $74.4 \%$ of the observed students, nevertheless, the academics that drink alcohol but do not visualize any alcohol-related content represent $56.1 \%$. As a outcome, an academic who visualizes alcohol content in the Snapchat social network has a risk of $1.36 \%$ ( $95 \% \mathrm{CI}=0.54$ to 5.16$)$ of consuming alcoholic beverage. 
Table 4 shows the distribution of reasons pointed by students, who consume alcohol, it is important mentioning that the participants were given

Table 3. Ratio of the frequency of visualization of alcohol content, with participants consuming alcoholic beverage or not in 2017/1, from the Federal University of Rondonia Foundation, Porto Velho, Brazil.

\begin{tabular}{cccc}
\hline \multirow{2}{*}{ Visualization } & \multicolumn{2}{c}{$\mathbf{f ( \% ) ^ { * }}$} & \multirow{R}{*}{ RO $\left(\mathrm{CI}^{* *}{ }_{95 \%}\right)$} \\
\cline { 2 - 3 } Facebook & Sim & Não & \\
yes & & & $3.34(1.92$ a 5.82$)$ \\
no & 65.8 & 34.2 & \\
Instagram & 53.3 & 46.7 & $3.30(1.89$ a 5.7$)$ \\
yes & & & \\
no & 74.1 & 25.9 & \\
Snapchat & 43.3 & 56.7 & $1.36(0.54$ a 5.16$)$ \\
yes & & & \\
no & 74.4 & 22.6 & \\
\hline
\end{tabular}

${ }^{\star}$ Relative Frequency, ${ }^{* *}$ Confidence Index.

Table 4. Reasons for university students to drink alcohol, resultas from the State University of Rondônia, Porto Velho, Brazil.

\begin{tabular}{|c|c|c|}
\hline \multirow{2}{*}{ Variable } & \multicolumn{2}{|c|}{$f(\%)^{*}$} \\
\hline & $2016 / 2$ & $2017 / 1$ \\
\hline \multicolumn{3}{|l|}{ Reasons to drink } \\
\hline It is fun & $14.83 \%$ & $11.94 \%$ \\
\hline To adapt to a group & $1.08 \%$ & $1.14 \%$ \\
\hline This way I will not fell alone & $0.53 \%$ & $0.56 \%$ \\
\hline Helps when I am sad or nervous & $2.98 \%$ & $3.40 \%$ \\
\hline My friends press me & $1.08 \%$ & $1.14 \%$ \\
\hline To get "happy" & $3.5 \%$ & $1.71 \%$ \\
\hline I like how it fells & 11.05 & $10.22 \%$ \\
\hline To make social gatherings more fun & $13.2 \%$ & $11.94 \%$ \\
\hline Celebrating a special occasion with friends & $19.14 \%$ & $21.02 \%$ \\
\hline To runaway of cares & $4.58 \%$ & $3.97 \%$ \\
\hline To get rid of the problems & $2.97 \%$ & $1.71 \%$ \\
\hline Helps when I am on a bad mood & $3.21 \%$ & $6.81 \%$ \\
\hline Feels good & $6.2 \%$ & $8.52 \%$ \\
\hline Makes me secure and self-confident & $2.7 \%$ & $4.55 \%$ \\
\hline Helps me to enjoy the parties & $5.67 \%$ & $5.11 \%$ \\
\hline It is exciting & $2.16 \%$ & $1.71 \%$ \\
\hline Makes me more sociable & $5.12 \%$ & $4.55 \%$ \\
\hline
\end{tabular}

${ }^{*}$ Relative Frequency. 
more than just a single choice. It was revealed out that during in the first application, $19.14 \%$ consumed alcohol "to celebrate a special time with friends", $14.83 \%$ "because it is fun", $13.2 \%$ "to make social gatherings more fun" and $11.05 \%$ "For liking the sensation".

During the second application period, "celebrating a special occasion with friends" continued to be the main reason why they consume drink, with $21.02 \%$, followed by $11.94 \%$, for "to make social gatherings more fun", $11.94 \%$ "For being fun", $10.22 \%$ liking how it feels and $8.52 \%$ for giving a nice feeling.

Regarding the scale of feeling of exposure from 0 (I do not feel exposed at all) to 10 (I feel totally exposed) to subjects with alcohol content, it is see that $31.2 \%$ of participants do not feel exposed and $38.5 \%$ stated to fell from moderate to fully exposed in 2016/2, by 2017/1,48.9\% report not feeling themselves exposed.

The analysis of drink consumption by the friends of the students shows us that in 2016/2 and 2017/1, almost all close friends of the participants drink alcoholic drinks with $38.6 \%$ and $33.4 \%$, respectively.

\section{Discussion}

Facebook is the social network with the most frequent alcohol content exposure, followed by Instagram and Snapchat, which contrasts with data from a similar research referring the United States where Snapchat is the medium with the highest incidence of viewing alcohol-related material among those starting college, followed by Instagram and Facebook [8].

Although Facebook was found the social media website with the largest number of users, the study showed that, despite being a new network, Snapchat has a greater impact of visualization and consumption, as it was the network with greater visualization of posts of an alcoholic character.

The data reveals that students entering the university have a medium age between 18 and 20 years old and already have previous drinking habits, pointed already by other studies [5] [9].

The impact of alcohol visualization and subsequent consumption on social media sites is not significant due to the fact that drinking habits are already seen in these age groups who are entering university, which leads to opposite outcomes from researches that have identified significant influence of these networks among students from the west coast of the United States, those mostly enter graduation with an average age of approximately 18 years and do not have a high alcohol consumption yet [9].

The explanations of why students ingest alcoholic beverages are corroborated by different researchers who conclude that celebrating a special occasion is the most cited explanation for alcohol intake in this age [6].

College life introduces to new friendships, with each student brings with them their habits, so when interacting with peers who consume alcoholic beverages, college freshmen become exposed, also as a consequence of posts in their social media, implying a subjective vulnerability to this content, where they often do 
not perceive itself influenced by the media.

Multiple studies have shown the influence of advertisements in the media on alcohol consumption among young people [10] and this is corroborated in this research, which identified that viewing alcoholic content on Facebook, Instagram and Snapchat influence on subsequent consumption. However, what has been observed is that this exposure in social networks is imperceptible on the part of the students [10].

\section{Conclusion}

Facebook was discovered as the social network most used among the students, in addition, there is an exposure to the alcoholic content both of the virtual media and from the personal network of friends, although imperceptible to the students, as they don't consider themselves exposed. Many freshmen enter university already with a previous history of drinking alcoholic substances, which explains why there is no significant change in alcohol consumption between the first and the second interviews, but it was found a relationship between the visualization of alcohol content in social networks and consumption of products, with greater impact on Snapchat. The main limitation of this study is that it was carried out at a single university in the Western Amazon, but these findings do point the way to future research.

\section{Acknowledgements}

The authors would like to express gratitude to the anonymous university students who took part in the present study and to the Institutional Program for Scholarship of Scientific Initiation (PIBIC) of the Federal University of Rondônia (UNIR), which enabled this study.

\section{Conflicts of Interest}

The authors declare no conflicts of interest regarding the publication of this paper.

\section{References}

[1] Andreassen, C.S., Pallesen, S. and Griffiths, M.D. (2017) The Relationship between Addictive Use of Social Media, Narcissism, and Self-Esteem: Findings from a Large National Survey. Addictive Behaviors, 64, 287-293. https://doi.org/10.1016/j.addbeh.2016.03.006

[2] Aleid, H., Alkhalaf, A.A., Taemees, A.H., Almurished, H.S., Alharbi, K.A. and Alanazi, N.H. (2018) Framework to Classify and Analyze Social Media Content. Social Networking, 7, 79-88. https://doi.org/10.4236/sn.2018.72006

[3] Ciribeli, J.P. and Paiva, V.H.P. (2011) Redes e mídias sociais na internet: realidades e perspectivas de um mundo conectado. Revista Mediação-Universidade FUMEC, 13, 57-74. http://www.fumec.br/revistas/mediacao/article/view/509

[4] World Health Organization Department of Mental Health and Substance Abuse, World Health Organization (WHO), Department of Mental Health and Substance 
Dependence and Department of Mental Health and Substance Abuse (2004) Global Status Report on Alcohol 2004. Alcohol, 1-94.

[5] Carneiro, A.L.M., Rodrigues, S.B., Gherardi-Donato, E.C.S., de Eliete, G.A.A. and Oliveira, V.C. (2011) Padrão do uso de álcool entre estudantes universitários da área da saúde. Revista de Enfermagem do Centro Oeste Mineiro, 1, 940-950.

[6] Faria, J.R., Ferreira, M.G., Lourenção, L.G. and Tavares, B.B. (2014) O consumo de álcool e a qualidade de vida de universitários da área da saúde. Arquivos de Ciências da Saúde, 21, 82-89.

[7] Cooper, M.L. (1994) Motivations for Alcohol Use among Adolescents: Development and Validation of a Four-Factor Model. Psychological Assessment, 6, 117-128. https://doi.org/10.1037/1040-3590.6.2.117

[8] Boyle, S.C., Labrie, J.W., Froidevaux, N.M. and Witkovic, Y.D. (2016) Addictive Behaviors Different Digital Paths to the Keg? How Exposure to Peers' Alcohol-Related Social Media Content in Fluences Drinking among Male and Female First-Year College Students. Addictive Behaviors, 57, 21-29.

https://doi.org/10.1016/j.addbeh.2016.01.011

[9] Maciel, M.E.D. and Vargas, D.De. (2017) Consumo de álcool entre estudantes de enfermagem Alcohol consumption among nursing students. Revista de Pesquisa: Cuidado é Fundamental Online, 9, 64. https://doi.org/10.9789/2175-5361.2017.v9i1.64-70

[10] Faria, R., Vendrame, A., Silva, R. and Pinsky, I. (2011) Propaganda de álcool e associação ao consumo de cerveja por adolescentes. Revista de Saúde Pública, 45, 441-447. https://doi.org/10.1590/S0034-89102011005000017 